\title{
Research progress on habitat connectivity in temperate waters
}

\author{
Shike $\mathrm{Gao}^{1}$ Wenwen $\mathrm{Yu}^{2}$, Zhen $\mathrm{Li}^{1}$, Shuo Zhang ${ }^{1,3,}{ }^{*}$, Kang Fu ${ }^{1}$, Nuo Wang ${ }^{1}$, Jun $\mathrm{Gu}^{1}$ \\ ${ }^{1}$ College of Marine Sciences, Shanghai Ocean University, Shanghai 201306, China \\ ${ }^{2}$ Jiangsu Research Institute of Marine Fisheries, Nantong 226007, Jiangsu, China \\ ${ }^{3}$ Joint Laboratory for monitoring and protection of aquatic biological resources in the Yangtze River \\ Estuary, Shanghai 200000, China
}

Shike Gao and Wenwen Yu contributed to the work equally and should be regarded as co-first authors.

*Corresponding author: Shuo Zhang ～E-mail: s-zhang@shou.edu.cn

\begin{abstract}
Ecological connectivity, as a research method related to spatial ecology and conservation biology, has attracted increasing attention from researchers at home and abroad in recent years. Habitat connectivity, as a key link in ecological connectivity, is of great significance to promote offshore ecological restoration and protection. However, there has been less systematic research about habitat connectivity, which lacks corresponding theories and practices. Therefore, this paper discusses habitat connectivity from three aspects: (1) the concept of habitat connectivity is introduced and clarified, (2) the application of connectivity in artificial habitat and adjacent waters and its relationship with biodiversity conservation are reviewed and illustrated with examples, and (3) the future development trends of this research direction are summarized and prospected, in order to provide a scientific basis and useful reference for the related work of offshore restoration projects in China. Generally, this paper argues that an increase in human behavior irreversibly destroys the connectivity of marine habitats and threatens the temporal scales of biodiversity and ecosystem services. Therefore, the theoretical research results and practical experience of ecological connectivity should be fully applied to marine ecosystems, and the restoration of degraded ecosystems should be encouraged and supported in ways that promote natural recovery.
\end{abstract}

Key words: habitat connectivity; movements of organisms; nutrient transport; offshore ecological restoration; artificial habitat; biodiversity conservation

\section{Introduction}

Through nutrient circulation and nutrient exchange between organisms, the offshore ecosystem has formed a spatial network structure that establishes connections between nutrients and energy fluxes across habitats and affects the stability of ecosystems and the trophic dynamic balance $[1,2]$. This cross-habitat coupling mechanism broadly exists among different marine ecosystems through water environments, organisms and other geochemical processes, which results in connectivity [3-7]. Connectivity determines the movements and diffusion of organisms, thus affecting the structure and function of an ecosystem [8-11]. Additionally, due to human disturbance (e.g., dams, waterways, and port construction) and global environmental changes (e.g., drought, climate warming, and ocean acidification), a large range of natural habitats has been destroyed, limiting the ability of species to migrate between habitats and ultimately blocking connectivity [12-15].

The targeted construction of artificial habitats is an effective way to increase connectivity in adjacent habitats [16]. The specific mechanism of this approach is to mediate the flows of water, sediment and organisms and then affect the community 
structure and diversity characteristics of aquatic organisms, thereby changing the ecosystem, ecological mode and connectivity between habitats [17, 18]. As early as the 17 th century, there was evidence that sunken structures could increase the development of underwater fisheries. For example, in Japan, some researchers have used sunken stones to increase the growth of macroalgae [19]. Subsequently, various types of substrates from concrete structures to logs and abandoned cars were used as artificial habitats [20-21]. Since the 1960s, several studies abroad have focused on the relationship between ecological connectivity transformation by the construction of artificial habitats and the complexity, stability and diversity of marine ecosystems [22-25], and these studies have laid a solid foundation for further research on promoting the spatial integrity of marine ecosystems and protecting habitat fragmentation. In recent years, domestic researchers have gradually investigated and studied marine ecological connectivity [26-29]. However, there is little research in related fields, and due to the lag in academic research and the lack of public awareness of related issues, ecological connectivity has not been established as part of the goal of protecting offshore ecosystems and biodiversity in China [30]; thus, it is urgent to carry out relevant investigation and research.

Based on the study of offshore ecological connectivity, the concept of habitat connectivity in this paper is introduced and clarified in detail. The application of connectivity in artificial habitats and adjacent waters and its relationship with biodiversity conservation are summarized and illustrated. The future development trends of this research direction are summarized and prospected to provide a scientific basis and useful reference for carrying out offshore ecological restoration projects and formulating habitat restoration strategies in China.

\section{Ecological connectivity and habitat connectivity}

Connectivity, a basic concept in topology, is broadly defined in ecology as the physical, chemical and biological processes and their interactions among ecosystems at all levels of the Earth, that is, ecological connectivity [31, 32]. Some researchers divide ecological connectivity into landscape connectivity and patch connectivity, while most ecologists divide it into structural connectivity and functional connectivity [28, 33,34]. Fang reviewed the definitions of ecological connectivity by many researchers and concluded that (1) ecological connectivity is based on species composition between habitats; (2) species can perceive different habitats through lateral, vertical, large and small-scale daily activities or seasonal migration; and (3) environmental changes in habitats will affect the flow of ecological resources among patches $[33,35]$. In other words, connectivity depends on the species and the environment, and connectivity can vary between species and habitats within the same ecosystem. Therefore, we divide ecological connectivity into habitat connectivity and functional connectivity. Habitat connectivity refers to the ability of organisms to make spatial connections between different habitats, thus regulating different aspects of the habitat. Functional connectivity describes the process of responding to single or multiple populations through the movement and diffusion of organisms between habitats [6, 36, 37]. Based on this, this paper focuses on the analysis of habitat connectivity in marine ecosystems. In the following articles, community, protected areas, patches and other spatial units are synonymous with the concept of "habitat" for convenience of description and induction. 


\section{The application of habitat connectivity in an ecosystem}

Because of its high spatial heterogeneity and dynamic characteristics, the offshore ocean is often selected as a key research area. Compared with terrestrial ecological connectivity, research on offshore ecological connectivity started late in the mid-1990s, and habitat connectivity has been a popular research topic in recent years $[6,25]$. In this paper, the Web of Science database was used to input the keyword marine habitat connectivity, and the search results produced 3095 articles, of which nearly 1500 articles were published in the past five years (Figure 1). Therefore, it is helpful to improve offshore ecological restoration and biological resource protection by discussing the relationship between population number and composition and the connectivity of offshore ecosystems.

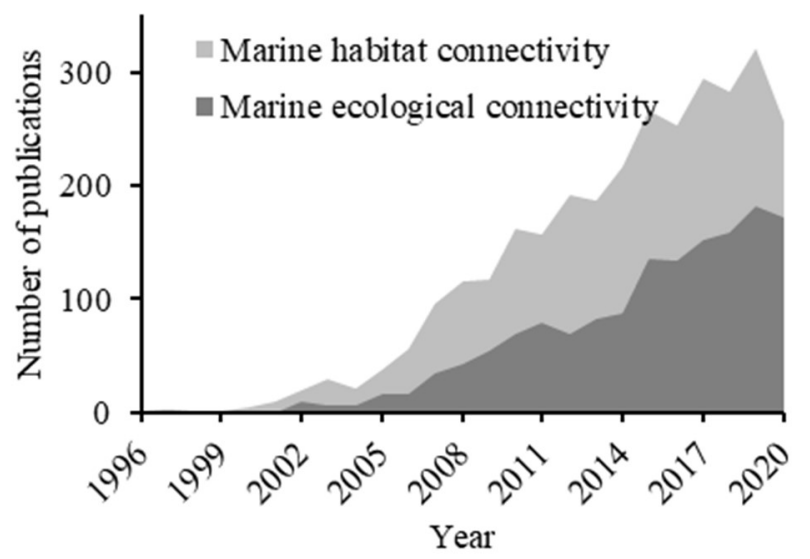

Figure 1. The number of articles published in the Web of Science database in different years based on the keywords marine ecological connectivity and marine habitat connectivity

\subsection{The main driving factors of habitat connectivity}

Connectivity mechanisms include the movements of organisms, hydrological cycles, nutrient transport and climate change processes [35]; additionally, the movements of organisms and transport of nutrients are the two most direct mechanisms that meet the nutrient requirements of organisms in different habitats [28] (Figure 2). Flitcroft proposed habitat patterns for freshwater, estuarine, and marine environments for Pacific salmon (Oncorhynchus spp.) that are important for population recovery and long-term conservation [38]. Quevedo found that the degree of niche differentiation in Eurasian perch, which has a broad diet in different habitats, may have a significant effect on habitat connectivity and trophic dynamics, suggesting that specific individuals can link spatially separated nutrient and energy flows to create new heterogeneity to restructure food webs [39-41]. Different species in the same habitat may also cause differences in connectivity due to their different feeding strategies [42]. Studies have shown that invasive species can lead to the extinction of native species, loss of regulatory functions (debris decomposition, etc.), and habitat changes, which in turn affect nutrient cycling and block connectivity [43]. In view of the rapid changes in aquatic biodiversity and the habitat environment, the regulation of the spatial and temporal characteristics of a complex ecosystem cannot be limited to a single habitat or species; rather, both habitat connectivity and functional connectivity should be considered simultaneously.

Both the movements of organisms and environmental changes will directly affect ecosystem productivity, habitat connectivity and suitability; additionally, there are other 
factors that affect the population growth of organisms [44], and these factors are directly related to nutrient transport patterns. This pattern usually contributes to the surface water and groundwater in the form of organic matter, which is transmitted between habitats in the ocean in the form of nutrients and sediments [45-47]. These nutrient inputs can change productivity [48], seafloor coupling [49, 50], biomass, and density [51], thereby functionally linking populations and ecological functional zones and allowing us to better understand and predict changes in marine ecosystems [7].

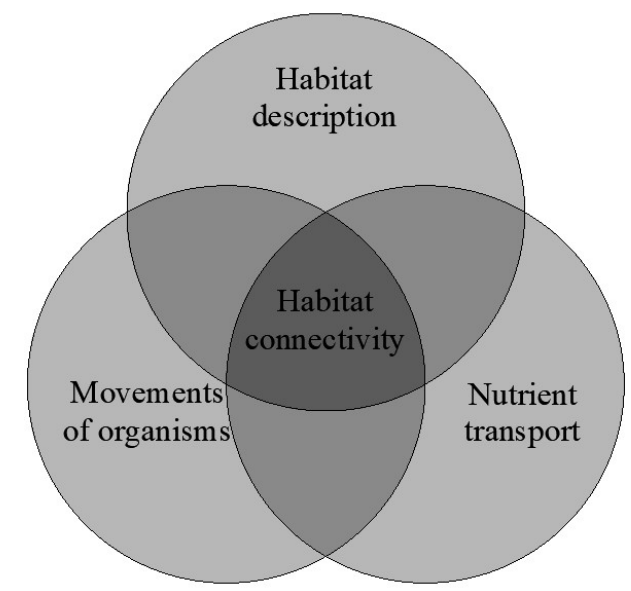

Figure 2. Venn diagram of the range of habitat connectivity in marine food webs, focusing on the links among habitat description, movements of organisms and nutrient transport (imitate Flitcroft [38])

Compared with the movements of organisms between habitats, there have been many studies on nutrient transport [52-54]. For example, when the artificial habitat is implemented on the sea bottom, the flow field effect generated around it must be considered $[55,56]$. In sea areas with high flow rates, different organic carbon sources are integrated in space under the influence of ocean currents, resulting in nutrient migration and making ocean currents the main driving force of nutrient transport. In this case, the water and sediments in the sea area become the main carriers of nutrient transport. For example, based on the concept of connectivity, Pearson applied the method of studying sediment path migration to the study of coastal sediment dynamics and proposed a new view of coastal system connectivity [57]. In areas with low flow rates, due to the lack of the physical force of ocean currents, organic matter is not evenly distributed in space, and most of the time, it relies on organisms as the medium to complete the process of nutrient transport $[58,59]$. Most of these organisms are benthic organisms that selectively ingest certain nutrients $[46,60]$. Studies have shown that in different areas of estuaries, nutrient gradients are formed in benthic organisms that cannot trace their food sources [61]. Allen studied two kinds of marine benthic invertebrates (Botrylloides violaceus and Bugula stolonifera) with complex life cycles and suggested that the dispersal changes of larvae from birth (egg-breaking movement) to settlement and the inter- intra-specific competition after settlement could reconstruct spatially dispersed habitats through internal nutrients [62]. Karen believed that the nutrient conversion and energy flow of sea urchins (Strongylocentrotus droebachiensis) between adjacent habitats play a key role in the construction of marine food webs [63]. In addition, benthic resources may influence the feeding behavior of omnivorous primary consumers, thus affecting the trophic levels of 
premium consumers [48], which may ultimately alter the natural convergence or separation between habitats. For example, the hermit crab (Clibanarius vittatus) is the prey of premium consumers, representing the organisms that link the coast to the offshore area, based on the carbon and nitrogen isotopic signals in their muscles that provide useful indicators for the assimilation of organic nutrients into ecosystems [64].

The mechanism of connectivity driven by ocean currents is faster than that driven by the movements of organisms [65]. For some offshore and semi-enclosed harbors, estuaries are often the main source of nutrient transport [47]. However, this undoubtedly increases the stress capacity of the estuaries, while an increase in artificial habitat can solve this problem [66]. Therefore, when ecosystems are subject to multiple disturbances (e.g., climate change, biological invasions, and human behavior), exploring the relationships between the movements of organisms and nutrient transport in artificial habitats and adjacent waters can provide a framework for researchers and managers [47, 67], thus providing an important theoretical basis for the formulation and implementation of offshore ecological restoration projects.

\subsection{Habitat connectivity and biodiversity conservation: A case study of offshore artificial habitats}

It is well known that the habitat types of tropical or subtropical offshore ecosystems are mainly composed of seagrass beds, wetlands, mangroves, coral reefs, etc. [68, 69]. The temperate offshore waters are not as rich in habitat types as the tropics, and they generally include seagrass, seaweed and other natural island reef areas [70-72] (Table 1). From a seascape perspective (considering the relationship between ecological functions and spatial patterns), the intensity of habitat connectivity and the relative importance of multiple habitats in temperate offshore waters have not received enough attention in contrast to the more studied tropical seas [73-75].

Table 1. Common habitat types and connectivity in temperate waters

\begin{tabular}{lll}
\hline Type & Connectivity & Reference \\
\hline Mangrove & $\begin{array}{l}\text { By providing breeding grounds, feeding grounds and } \\
\text { protection from predators for the development and } \\
\text { migration of individual coral reef fish, they establish } \\
\text { relationships with other habitats }\end{array} \quad[76,77]$ \\
& $\begin{array}{l}\text { The abundance of the fish population was not high } \\
\text { when favorable spatial features were provided for } \\
\text { individuals (feeding field and avoiding field) }\end{array} \quad[76-78]$ \\
Seagrass & $\begin{array}{l}\text { Associations between populations are constructed } \\
\text { through the diffusion of individuals (juveniles and } \\
\text { adults) or between populations in different habitats } \\
\text { through the exchange of eggs, juveniles, and adults }\end{array} \quad[77,79]$ \\
Coral reef & $\begin{array}{l}\text { An increase in the abundance of fish populations and } \\
\text { changes to the community structure through the } \\
\text { creation of artificial habitats that are linked to the } \\
\text { surrounding habitats }\end{array}$ & {$[17,80]$} \\
Artificial reef & & \\
\hline
\end{tabular}


Serves as a primary producer and supports the

Seaweed aggregation of unique and diverse fish larvae and adults

The hard bottoms, which are not covered by

Rocky bottom habitats vegetation, are associated with other habitats and are second only to mangroves and coral reefs in terms of fish abundance

The soft bottom, which is not covered by vegetation,

Sandy habitats is slightly more abundant than the seagrass bed in relation to other habitats

Muddy habitats

Same with sandy habitats

$[78,82]$

Understanding the mechanisms of species extinction, the main drivers of which are habitat loss and fragmentation, is the core issue of biodiversity conservation [83]. To solve the impact of this problem on the dynamics of marine ecosystems, many coastal countries have begun to create artificial habitats to restore habitat. For example, in 1979, China implemented the use of artificial reefs to influence the surrounding water environment and biological distribution through human intervention [84-87]. However, the impact of artificial habitat construction on habitat connectivity is complex and variable. On the one hand, the compensatory effect of artificial habitat has a considerable time lag, and the generation of habitat connectivity with the surrounding adjacent waters requires clear temporal dynamics [88]. On the other hand, the restoration of human-damaged habitat connectivity requires empirical studies from four aspects: individual trophic ecology (birth rate, death rate, etc.), community structure characteristics, movements and diffusion of organisms, and their tolerance limits to the environment [89]. This means that it is necessary to consider the multiple and complex impacts and consequences if human interventions change habitat connectivity.

Over the past 10 years, there have been a number of examples of improving offshore ecological connectivity through the construction of artificial habitats. Keller believed that artificial reefs could increase the connectivity between adjacent habitats and contribute to the diffusion of benthic species [17]. Wu's research showed that artificial reefs could imitate natural habitats, which is conducive to the study of functional connectivity and the comprehensive management of artificial reefs and natural sea areas [90]. Diana argued that the connectivity between adjacent habitats in shallow water environments depended on highly similar species compositions and distribution patterns of fish, illustrating that habitat type was related to fish population size rather than biodiversity [78] (habitat types are shown in Table 1). Biodiversity is related to the complexity of the habitat, and the more complex the habitat structure is, the more abundant the species will be [91,92]. Van showed that neither habitat type nor habitat area could be used as a key factor to predict habitat connectivity, but its combination with the surrounding water environment should be considered [81]. In addition, habitat connectivity can be affected by habitat configuration, which is how habitats are arranged and spaced in an ecosystem [16]. Belmaker deployed pairs of artificial reefs at distances of 12 and $25 \mathrm{~m}$ from a large contiguous reef group and 
added four connecting reefs at 2.5-m intervals per pair on half of the artificial reefs. The results showed that artificial reefs with no connecting reef maintained 57 times as many individuals as the connecting reefs. However, the fish abundance increased with distance from $12 \mathrm{~m}$ to $25 \mathrm{~m}$, indicating that the fish abundance increased with increasing connecting reef distance, and the fish abundance fluctuation decreased with increasing connectivity, which may be the result of fish aggregation from the isolated reef after sudden migration [93]. Therefore, when planning and deploying artificial reefs in the future, managers should consider the configuration and proximity between reefs and natural habitats to increase the possibility of supplementing fish stocks and reducing the risk of target fishing mortality at artificial reefs.

In summary, although research on rebuilding habitat connectivity through the construction of artificial habitats has made rapid progress in recent years, the consideration of only a single factor or habitat is not comprehensive enough to effectively mitigate these impacts. At present, it is still unclear how the introduction of artificial structures can change the connectivity by affecting the structure and function of marine ecosystems [94]. In the author's opinion, it is an important trend for the future development of offshore ecological restoration to change or rebuild habitat connectivity by combining multiple scales and regions to shape and improve management actions related to marine protected areas (MPAs) or biodiversity.

\section{Research on the methods of habitat connectivity}

There are many methods and a wide range of methods for habitat connectivity. Previously, it was reported that the research methods were "spatial and time scale selection - biological distribution survey - structural connectivity analysis-functional connectivity analysis" [28]. Referring to its model, this paper divided the research methods of connectivity into the steps shown in Figure 3, and the key feature was an analysis of habitat connectivity and functional connectivity.

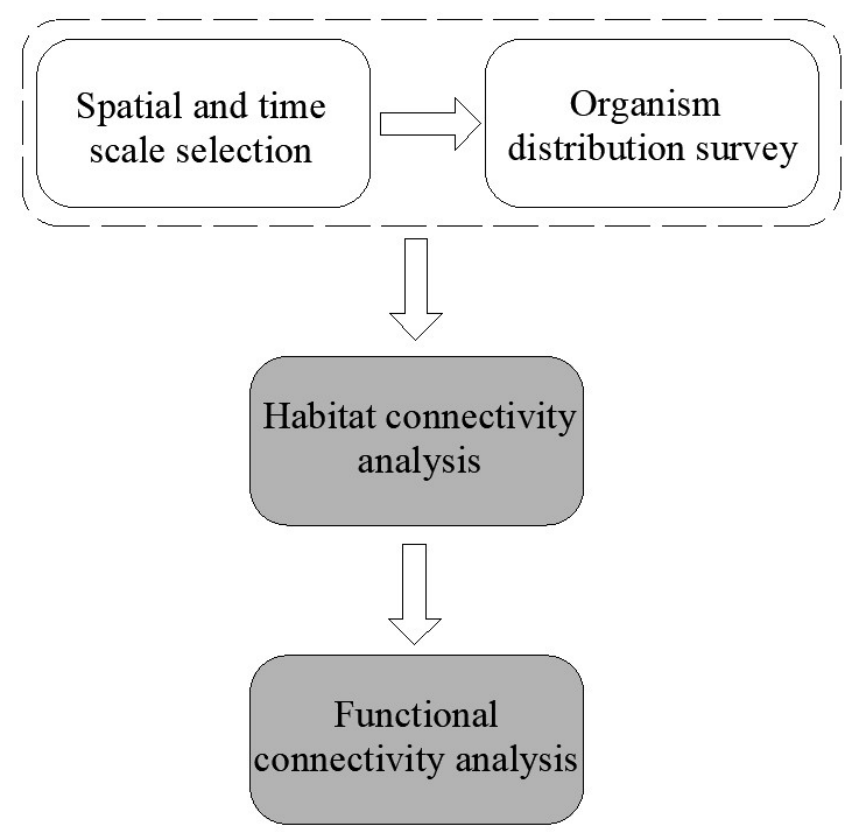

Figure 3. Flow chart of methods of connectivity in marine ecosystems 


\subsection{Habitat connectivity analysis}

Habitat connectivity can be analyzed by a variety of methods, such as field surveys, mark-recapture methods, telemetry, genetics, otolith microchemistry, and stable isotope analysis, which provide a powerful research tool for understanding habitat connectivity across temporal and spatial scales $[11,47,59,78,95]$. At present, diving observations, remote underwater video and mark-recapture methods are still widely used by foreign researchers, but the disadvantages of these methods include the heavy workload and limited research area; additionally, these methods often require temporal scale and dynamic changes $[11,16,82,96]$. Acoustic telemetry, radio telemetry and other technologies are advanced and mature, but these methods often lead to higher transmitter loss and greatly increase the expenditure when collecting a large amount of data $[17,97,98]$. In recent years, genetic methods have become the main way to analyze habitat connectivity. Compared with the traditional morphological identification method, genetic methods reduce the research cost of each sample [99, 100]. For example, Yamanaka used environmental DNA (eDNA) to compare three kinds of keystone species in three tributaries of the Yodo River in Japan and confirmed that there was habitat connectivity between rivers and seas [101]. In China, stable isotopes and other chemical methods are still used [102], but with the improvements and updates in biomolecular technology, the combination of genetics and biochemical methods has been advocated by an increasing number of researchers [103, 104]; this new approach provides more feasible schemes and broad prospects for studying the connectivity of offshore habitats in China.

\subsection{Functional connectivity analysis-numerical model analysis}

Functional connectivity analysis is based on biological distribution surveys and habitat connectivity analysis, which mainly focus on constructing different numerical models, namely, the biological information and environmental information of multiple habitats are constructed into proxy models to analyze, simulate and predict the structure and function of communities. For example, Aldea identified 13 single-sequence repeated markers on Colossoma macropomum in the Amazon River and applied model testing to prove that highly variable genetic data could be used to detect the connectivity of typical migratory fish [99]. Usually, a large amount of relevant data appears in various scientific studies; however, how to best integrate all of this information into a coherent conceptual and quantitative framework remains a major challenge $[89,105]$. White summarized the numerical models of larval movements and diffusion constructed by many researchers, described the key stages and processes of the use of different habitats in fish life history stages, and clarified that the key to understanding how marine spatial planning and marine reserves affect population and community dynamics is by linking the migration and diffusion process models of benthos and pelagic organisms under the application background [104].

In the past ten years, numerical ecosystem models have been widely used in China. Liu constructed the ecosystem structure and function of Laoshan Bay artificial reef areas based on the Ecopath model [106]. Wang constructed a 10-year Ecopath model of Haizhou Bay MPAs dominated by artificial reefs, and the results proved that Haizhou Bay gradually developed into a relatively mature system from 2003 to 2013 [107]. Liao developed a patch dynamics model and found that each module could produce unique species survival patterns in fragmented habitats [83]. Therefore, the method of constructing a numerical 
model to study functional connectivity is worth further research. However, there is always a common problem of insufficient data in numerical model research. In the future, in the process of exploring the relationship between marine ecosystems and habitat connectivity, we could create a more efficient and high-quality method by combining various methods and integrating habitat information to construct a composite model.

\section{Problems and prospects}

Domestic research on marine ecological connectivity is still in its infancy, with no systematic research being conducted yet, and there are few studies on either habitat connectivity or functional connectivity. The offshore ocean is the core area where habitat connectivity is generated. However, habitat fragmentation (loss of habitat connectivity, edge effects and habitat loss) caused by the increase in human activities can have a strong impact on population abundance and seriously threaten biodiversity in any environment [108]. In marine conservation work, the link between landscape ecology and marine spatial planning can be strengthened, the spatial scale of ecological functions and conservation effects regulated by connectivity can be determined [109], and the community structure and habitat fragmentation can be considered simultaneously [83].

In fact, it is better to study the ecosystem structure and function between adjacent habitats through habitat connectivity, and there is much room for research. The main purpose of such studies is to explore the relationship between spatial distribution and functional areas and their interaction on community dynamics, and this research can be carried out from the following aspects in the future:

(1) Each habitat has a unique set of habitats and species, but they are still related to each other. Therefore, the organism assemblage and community similarity between different habitats can be studied through difference and diversity analysis $[29,82,110]$.

(2) Key species are the basic drivers of ecosystem processes and can reorganize the community structure by imposing restrictions on other species through predation or resource allocation. The general effects of protozoa, plankton and benthos on offshore ecosystems have been demonstrated and can be considered as research objects [111-113].

(3) To explore the effects of movements of organisms and nutrient transport patterns on habitat connectivity, which should mimic ecosystems and focus on the integrity, heterogeneity and interconnection between different habitats [78]; additionally, we can focus on the interaction and influence of different habitats on the dynamics of the surrounding complex ecological community and construct a complex food web model to study habitat connectivity.

Regardless of perspective, the ultimate purpose of habitat connectivity research is to restore or rebuild habitats and protect ecosystems and biodiversity [7]. In the context of today's reduced productivity and connectivity, the impact on the global offshore ocean is continually worsening, and there is no way to reverse this process [13, 25]. However, aggressive regulatory actions have been taken, and recent developments suggest that there is hope in this area $[114,115]$. Although great progress has been made in establishing habitat connectivity through human intervention, effective restoration methods are not yet available. Therefore, we should do more to protect existing biodiversity, ensure the continuation of our healthy marine ecosystems and their important services, and actively restore and remedy degraded ecosystems by promoting natural recovery. 


\section{Acknowledgments}

This study was financed by the Jiangsu Haizhou Bay National Sea Ranching Demonstration Project (D-8005-18-0188) and supported in part by the Science Foundation for Youths of Jiangsu Province, China (BK20170438), and the Science and Technology Projects in Nantong (JC2018014).

\section{Data Availability statement}

The data that support the findings of this study are available from the corresponding author [Shuo Zhang], upon reasonable request.

\section{References}

1. Paine; Robert, T. Food web complexity and species diversity. American Naturalist; 1966, 100, 65-75.

2. Schindler; D.E.; Scheuerell; M.D. Habitat coupling in lake ecosystems. Oikos. 2002, 98, 177-189.

3. Polis, G.A.; Holt, A.R.D. Toward an integration of landscape and food web ecology, The dynamics of spatially subsidized food webs. Annual Review of Ecology \& Systematics. 1997, 28, 289-316.

4. Vinagre, C.; João Salgado; Cabral, H.N.; et al. Food Web Structure and Habitat Connectivity in Fish Estuarine Nurseries - Impact of River Flow. Estuaries and Coasts. 2011, 34, 663-674.

5. Stanley, C.E.; Taylor, J.M.; King, R.S. Coupling Fish Community Structure with Instream Flow and Habitat Connectivity between Two Hydrologically Extreme Years. Transactions of the American Fisheries Society. 2012, 141, 1000-1015.

6. Lecraw, R.M.; Kratina, P.; Srivastava, D.S. Food web complexity and stability across habitat connectivity gradients. Oecologia. 2014, 176, 903-915.

7. Zuercher, R.; Galloway, A.W.E. Offshore ecosystem connectivity, pelagic ocean to kelp forest subsidies. Ecosphere. 2019, 10, e02602.

8. Fullerton, A.H.; Burnett, K.M.; Steel, E.A.; et al. Hydrological connectivity for riverine fish, measurement challenges and research opportunities. Freshwater Biology. 2010, 55, 2215-2237.

9. Muir, W.D.; Williams, J.G. Improving connectivity between freshwater and marine environments for salmon migrating through the lower Snake and Columbia River hydropower system. Ecological Engineering. 2012, 48, 19-24.

10. Caldwell; Iain, R.; Gergel; Sarah, E. Thresholds in seascape connectivity, influence of mobility; habitat distribution; and current strength on fish movement. Landscape Ecology. 2013, 28, 1937-1948.

11. Perez, A.U.; Schmitter-Soto, J.J.; Adams, A.J.; et al. Connectivity mediated by seasonal bonefish (Albula vulpes) migration between the Caribbean Sea and a tropical estuary of Belize and Mexico. Environmental Biology of Fishes. 2019, 102, 197-207.

12. Driver, L.J.; Hoeinghaus, D.J. Fish metacommunity responses to experimental drought are determined by habitat heterogeneity and connectivity. Freshwater Biology. 2016, 61, 533-548.

13. Juergen, G.; Stephen, J.H.; Frederick, W.A.; et al. Habitat recovery and restoration in aquatic ecosystems current progress and future challenges. Aquatic Conserv, Mar. Freshw. Ecosyst. 2016, 26, 942-962. 
14. Nehir, K.; Winemiller, K.O.; Senol, A.; et al. Spatial and temporal variation in food web structure of an impounded river in Anatolia. Marine and Freshwater Research. 2018, 69, 1453-1471.

15. Horn, H.G.; Boersma, M.; Garzke, J.; et al. High CO 2 and warming affect microzooplankton food web dynamics in a Baltic Sea summer plankton community. Marine Biology. 2020, 167, 1-17.

16. Dorenbosch, M.; Verberk, W.C.; Nagelkerken, I.; et al. Influence of habitat configuration on connectivity between fish assemblages of Caribbean seagrass beds; mangroves and coral reefs. Marine Ecology Progress Series. 2007, 334, 103-116.

17. Keller, K.; Smith, J.A.; Lowry, M.B.; et al. Multispecies presence and connectivity around a designed artificial reef. Marine \& Freshwater Research. 2017, 68; 1489-1500.

18. Reeds, K.A.; Smith, J.A.; Suthers, I.M.; et al. An ecological halo surrounding a large offshore artificial reef, Sediments; infauna; and fish foraging. Marine Environmental Research. 2018, 141, 30-38.

19. Choi, C.G.; Ohno, M.; Sohn, C.H. Algal Succession on Different Substrata Covering the Artificial Iron Reef atlkata in Shikoku; Japan. Choryu-Hakhoe-chi / The Korean Journal of Phycology. 2006, 21, 305-310.

20. Seaman, W.; Sprague, L.M. Artificial habitat practices in aquatic systems. In, Seaman; W. and Sprague; L.M. eds. Artificial Habitats for Marine and Freshwater Fisheries. Academic Press Inc. San Diego. 1991, 1-29.

21. Baine, M. Artificial reefs, a review of their design; application; management and performance. Ocean and Coastal Management. 2001, 44, 241-259.

22. Thorsten, B.; Susa, N. 4.16-Biodiversity - Marine Food-Web Structure; Stability; and Regime Shifts. Climate Vulnerability. 2013, 203-212.

23. Bergamino, L.; Richoux, et al. Stable isotope evidence of food web connectivity by a top predatory fish (Argyrosomus japonicus, Sciaenidae, Teleostei) in the Kowie Estuary; South Afric. African Journal of Marine Science. 2014, 36, 207-213.

24. Pittman, S.J.; Monaco, M.E.; Friedlander, A.M.; et al. Fish with Chips, Tracking Reef Fish Movements to Evaluate Size and Connectivity of Caribbean Marine Protected Areas. Plos One. 2014, 9, e96028.

25. Dias B S; Frisk M G; Jordaan A. Opening the tap, Increased riverine connectivity strengthens marine food web pathways. PLOS ONE. 2019, 14, e0217008.

26. Liu, X.; Wang, H. Effects of loss of lateral hydrological connectivity on fish functional diversity. Conservation Biology. 2018, 32, 1336-1345.

27. Li, W.; Li, H.; Zhou, D.; et al. Modelling Hydrological Connectivity in the MarineFreshwater Interaction in the Yellow River Estuary of China. Wetlands. 2020, 40, 28252835.

28. Du, J.G.; Ye, G.Q.; Zhou, Q.L. et al. Progress and prospects of offshore ecological connectivity studies. Acta Ecologica Sinica. 2015, 35, 6923-6933. (In Chinese)

29. Du, J.; Xie, M.; Wang, Y.; et al. Connectivity of fish assemblages along the mangroveseagrass-coral reef continuum in Wenchang; China. Acta Ecologica Sinica. 2020, (6179).

30. Ministry of Environmental Protection. China's Fourth National Report on the Implementation of the Convention on Biological Diversity [M]. Beijing, China Environmental Science Press. 2009. (In Chinese)

31. White, D.; Kiester, A.R. Topology matters, Network topology affects outcomes from 
community ecology neutral models. Computers Environment and Urban Systems. 2008, $32,327$.

32. Sheaves, M. Consequences of ecological connectivity, the coastal ecosystem mosaic. Marine Ecology Progress. 2009, 393, 107-115.

33. Tischendorf, L.; Fahrig, L. On the usage and measurement of landscape connectivity. Oikos. 2000, 90, 7-19.

34. Bradbury, I.R.; Snelgrove, P.V.R.; Bentzen, P.; et al. Structural and functional connectivity of marine fishes within a semi-enclosed Newfoundland fjord. Journal of Fish Biology. 2010, 75, 1393-1409.

35. Fang, X.; Hou, X.; Li, X.; et al. Ecological connectivity between land and sea, a review. Ecological Research, 2018, 33, 51-61.

36. Moilanen, A.; Nieminen, M. Simple connectivity measures in spatial ecology. Ecology. 2002, 83, 1131-1145.

37. Opermanis, O.; MacSharry, B.; Aunins, A.; Sipkova, Z. Connectedness and connectivity of the Natura 2000 network of protected areas across country borders in the European Union. Biol Conserv. 2012, 153, 227-238.

38. Flitcroft, R.L.; Arismendi, I.; Santelmann, M.V. A Review of Habitat Connectivity Research for Pacific Salmon in Marine; Estuary; and Freshwater Environments. JAWRA Journal of the American Water Resources Association. 2018, 55, 430-441.

39. Rooney, N.; Mccann, K.; Gellner, G.; et al. Structural asymmetry and the stability of diverse food webs. Nature. 2006, 442, 265-269.

40. Quevedo, M.; Svanbck, R.; Eklv, P. Intrapopulation niche partitioning in a generalist predator limits food web connectivity. Ecology. 2009, 90, 2263-74.

41. Rezende, E.L.; Albert, E.M.; Fortuna, M.A.; et al. Compartments in a marine food web associated with phylogeny; body mass; and habitat structure. Ecology Letters. 2010, 12, 779-788.

42. Dance, M.A.; Rooker, J.R. Habitat- and bay-scale connectivity of sympatric fishes in an estuarine nursery. Estuarine Coastal \& Shelf ence. 2015, 167, 447-457.

43. Manenti, R.; Ghia, D.; Fea, G.; et al. Causes and consequences of crayfish extinction, Stream connectivity; habitat changes; alien species and ecosystem services. Freshwater Biology. 2019, 64, 284-293.

44. Garcia, A.M.; Winemiller, K.O.; Hoeinghaus, D.J.; et al. Hydrologic pulsing promotes spatial connectivity and food web subsidies in a subtropical coastal ecosystem. Marine Ecology Progress. 2017, 567, 17-28.

45. Anderson, W.B.; Wait, D.A.; Stapp, P. Resources from another place and time, responses to pulses in a spatially subsidized system. Ecology. 2008, 89, 660-70.

46. Connolly, R.M.; Schlacher, T.A.; Gaston, T.F. Stable isotope evidence for trophic subsidy of coastal benthic Garcia fisheries by river discharge plumes off small estuaries. Marine Biology Research. 2009, 5, 164-171.

47. Laske, S.M.; Rosenberger, A.E.; Wipfli, M.S.; et al. Surface water connectivity controls fish food web structure and complexity across local- and meta-food webs in Arctic Coastal Plain lakes. Food Webs Journal. 2019, 21, e00123.

48. Reid, M.A.; Delong, M.D.; Thoms, M.C. The influence of hydrological connectivity on food web structure in floodplain lakes. River Research \& Applications. 2012, 28, 827-844.

49. Dias, E.; Morais, P.; Cotter, A.M.; et al. Estuarine consumers utilize marine; estuarine 
and terrestrial organic matter and provide connectivity among these food webs. Marine Ecology Progress Series. 2016, 554, 21-34.

50. Gladstone-Gallagher, R.V.; Mangan, S.; Thrush, S.F.; et al. Porewater nutrient enrichment alters benthic-pelagic coupling on intertidal sandflats. Journal of Sea Research. 2020, 159, 101876.

51. Mattocks, S.; Hall, C.J.; Jordaan, A. Damming; Lost Connectivity; and the Historical Role of Anadromous Fish in Freshwater Ecosystem Dynamics. BioScience. 2017, 67, 713-728.

52. Treml, E.A.; Halpin, P.N.; Urban, D.L.; et al. Modeling population connectivity by ocean currents; a graph-theoretic approach for marine conservation. Landscape Ecology; 2008, 23, 19-36.

53. Karen; Wild-Allen; John; et al. Connectivity between estuaries influences nutrient transport; cycling and water quality. Marine Chemistry. 2016, 185, 12-26.

54. Japaud; Aurélien; Bouchon, C.; Magalon; Hélène; et al. Geographic distances and ocean currents influence Caribbean Acropora palmata population connectivity in the Lesser Antilles. Conservation Genetics. 2019, 20, 447-466.

55. Liu, T.L.; Su, D.T. Numerical analysis of the influence of reef arrangements on artificial reef flow fields. Ocean Engineering. 2013, 74, 81-89.

56. Zalmon, I.R.; Sa, F.S.D.; Neto, E.J.D.; et al. Impacts of artificial reef spatial configuration on infaunal community structure - Southeastern Brazil. Journal of Experimental Marine Biology \& Ecology. 2014, 454, 9-17.

57. Pearson, S.G.; Prooijen, B.C.V.; Elias E P L; et al. Sediment Connectivity, A Framework for Analyzing Coastal Sediment Transport Pathways. Journal of Geophysical Research, Earth Surface. 2020, 125, e2020JF005595.

58. Rosenblatt, A.E.; Heithaus, M.R. Does variation in movement tactics and trophic interactions among American alligators create habitat linkages. Journal of Animal Ecology; 2011, 80, 786-798.

59. Howe, E.R.; Simenstad, C.A. Using stable isotopes to discern mechanisms of connectivity in estuarine detritus-based food webs. Marine Ecology Progress. 2015, 518, 13-29.

60. Conway-Cranos, L.; Kiffney, P.; Bana,s N.; et al. Stable isotopes and oceanographic modeling reveal spatial and trophic connectivity among terrestrial; estuarine; and marine environments. Marine Ecology Progress. 2015, 533, 15-28.

61. Emily; Howe; Charles, A.; et al. Detrital shadows, estuarine food web connectivity depends on fluvial influence and consumer feeding mode. Ecological applications. 2017, 27, 2170-2193.

62. Allen, R.M. Variation in dispersal and competitive ability mediate realized connectivity in two benthic marine invertebrates. Marine Biology. 2017, 164, 216.

63. Karen, F.D. Detrital kelp subsidy supports high reproductive condition of deep-living sea urchins in a sedimentary basin. Aquatic Biology. 2014, 23, 71-86.

64. Gorman, D.; Pucci, M.; Soares, L.S.H.; et al. Land-Ocean Connectivity Through Subsidies of Terrestrially Derived Organic Matter to a Nearshore Marine Consumer. Ecosystems. 2019, 22, 796-804.

65. Mélanie; Raimonet; James, E.; Cloern. Estuary-ocean connectivity, fast physics; slow biology. Global Change Biology. 2017, 23, 2345-2357.

66. Folpp, H.R.; Schilling, H.T.; Clark, G.F.; et al. Artificial reefs increase fish abundance 
in habitat-limited estuaries. Journal of Applied Ecology. 2020, 57, 1752-1761.

67. Thompson, R.M.; Brose, U.; Dunne, J.A.; et al. Food webs, reconciling the structure and function of biodiversity. Trends in Ecology and Evolution. 2012, 27, 689-697.

68. Martijn, D.; Monique, G.G.; Martijn, J.A.; et al. Indo-Pacific seagrass beds and mangroves contribute to fish density and diversity on adjacent coral reefs. Marine ecology progress series. 2005, 302, 63-76.

69. Nagelkerken; Ivan. Ecological Connectivity among Tropical Coastal Ecosystems; Springer Netherlands. 2009, 533-564.

70. Jackson, E.L.; Attrill, M.J.; Jones, M.B. Habitat characteristics and spatial arrangement affecting the diversity of fish and decapod assemblages of seagrass (Zostera marina) beds around the coast of Jersey (English Channel). Estuarine Coastal \& Shelf ence. 2006, 68, 421-432.

71. Page, H.M.; Dugan, J.E.; Lenihan, H.; et al. Trophic links and condition of a temperate reef fish, comparisons among offshore oil platform and natural reef habitats. Marine Ecology Progress. 2007, 344, 245-256.

72. Yoshinaga, K. Ontogenetic habitat shift in yearling surfperch Ditrema temmincki pacificum from a seagrass bed to a seaweed bed at Tateyama; central Japan. うみ Umi. 2012, 50, 85-89.

73. Lapoint, S.; Balkenhol, N.; Hale, J.; et al. Ecological connectivity research in urban areas. Functional Ecology. 2015, 29, 868-878.

74. Perry, D.; Staveley, T.A.B.; Hammar, L.; et al. Temperate fish community variation over seasons in relation to large-scale geographic seascape variables. Canadian Journal of Fisheries and Aquatic ences. 2018, 75, 1723-1732.

75. Staveley, T.A.B.; Perry, D.; Lindborg, R.; et al. Seascape structure and complexity influence temperate seagrass fish assemblage composition. Ecography. 2016, 40, 936946.

76. Unsworth, R.K.F.; Leon, P.S.D.; Garrard, S.L.; et al. High connectivity of Indo-Pacific seagrass fish assemblages with mangrove and coral reef habitats. Marine Ecology Progress. 2008, 353, 213-224.

77. Charlotte, B.; Tove, L.J.; Micaela, H. Ecological connectivity and niche differentiation between two closely related fish species in the mangrove-seagrass-coral reef continuum. Marine Ecology Progress Series. 2013, 477, 201-215.

78. Diana; Perry; Thomas, A.B.; Staveley; Martin, Gullström. habitat connectivity of fish in temperate shallow-water seascapes. Frontiers in Marine Science. 2018, 4, 440.

79. Wu R. Progress in Studies of Connectivity among Coral Reefs. Wetland Science \& Management. 2016, 12, 53-57. (In Chinese)

80. Logan, R.K.; Lowe, C.G. Residency and inter-reef connectivity of three gamefishes between natural reefs and a large mitigation artificial reef. Marine Ecology Progress Series. 2018, 593, 111-126.

81. Van, L.J.R.; Wilson, S.K.; Martial, D.; et al. Habitat connectivity and complexity underpin fish community structure across a seascape of tropical macroalgae meadows. Landscape Ecology. 2018, 33, 1-14.

82. Reis-Filho, J.A.; Schmid, K.; Harvey, E.S.; et al. Coastal fish assemblages reflect marine habitat connectivity and ontogenetic shifts in an estuary-bay-continental shelf gradient. Marine Environmental Research. 2019, 148, 57-66.

83. Liao, J.B.; Daniel, B.; Wang, Y.Q. et al. Robustness of metacommunities with omnivory 
to habitat destruction, disentangling patch fragmentation from patch loss. Ecology. 2017, 98, 1631-1639.

84. Zhang, H.H.; Sun, L. On reproduction increase of the sea aquatic resources by artificial fish-reef engineering. Resources Science. 2001, 23, 6-10. (In Chinese)

85. Chen, Y; Yu, C.Q.; Zhang, G.S.; et al. The environmental function and fish gather effect of atificial reefs. Journal of dalian fisheries university; 2002, 64-69. (In Chinese)

86. Wu, Z.; Zhang, X.; Lozano-Montes, H.M.; et al. Trophic flows; kelp culture and fisheries in the marine ecosystem of an artificial reef zone in the Yellow Sea. Estuarine Coastal and Shelf ence. 2016, 182, 86-97.

87. Yang, H.S. Construction of marine ranching in China, reviews and prospects. Journal of Fisheries of China. 2016, 40, 1133-1140. (In Chinese)

88. Walker, S.J.; Schlacher, T.A. Limited habitat and conservation value of a young artificial reef. Biodiversity \& Conservation. 2014, 23, 433-447.

89. David, A.C.; Winsor, H.L.; Frederick, W.A.; et al. Human effects on ecological connectivity in aquatic ecosystems, Integrating scientific approaches to support management and mitigation. Science of the Total Environment. 2015, 534, 52-64.

90. Wu, Z.X.; Tweedley, J.; Loneragan, N.; et al. Artificial reefs can mimic natural habitats for fish and macroinvertebrates in temperate coastal waters of the Yellow Sea. Ecological Engineering. 2019, 23, 6-10.

91. Gullstroem, M.; Bodin, M.; Nilsson, P.G.; et al. Seagrass structural complexity and landscape configuration as determinants of tropical fish assemblage composition. Marine Ecology Progress. 2008, 363, 241-255.

92. Henderson, C.J.; Gilby, B.L.; Lee, S.Y.; et al. Contrasting effects of habitat complexity and connectivity on biodiversity in seagrass meadows. Marine Biology. 2017, 164, 117.

93. Belmaker, J; Ziv, Y.; Shashar, N. The influence of connectivity on richness and temporal variation of reef fishes. Landscape Ecology. 2011, 26, 587-597.

94. Bishop, M.J.; Mayer-Pinto, M.; Airoldi, L.; et al. Effects of ocean sprawl on ecological connectivity, impacts and solutions. Journal of Experimental Marine Biology \& Ecology. 2017, 492, 11-24.

95. Thaís, R.M.; Esteban, A.; Barbara, M.C.; et al. Population structure and habitat connectivity of Genidens genidens (Siluriformes) in tropical and subtropical coasts from Southwestern Atlantic. Estuarine; Coastal and Shelf Science. 2020, 242, 106839.

96. Mosman. J.D.; Henderson, C.J.; Olds, A.D.; et al. Seascape connectivity exerts differing effects for fish assemblages in distinct habitats of the surf zones of ocean beaches. ICES Journal of Marine ence. 2020, 3.

97. Cooke, S.J.; Midwood, J.D.; Thiem, J.D.; et al. Tracking animals in freshwater with electronic tags, past; present and future. Animal Biotelemetry. 2013, 1, 1-19.

98. Doug, P.A.; Nikki, M.A.; Susanne, G.; et al. Using radio-tracking data to predict postrelease establishment in reintroductions to habitat fragments. Biological Conservation. 2013, 168, 152-160.

99. Aldea, G; María, I.; Hargrove, J.; Austin, J.D. Diversity and geneflow in a migratory frugivorous fish, implications for Amazonian habitat connectivity. Conservation Genetics. 2013, 14, 935-942.

100. Sigsgaard, E.E.; Carl, H.; Møller, P.R.; et al. Monitoring the near-extinct European weather loach in Denmark based on environmental DNA from water samples. Biological Conservation. 2015, 183, 46-52. 
101. Yamanaka, H.; Minamoto, T. The use of environmental DNA of fishes as an efficient method of determining habitat connectivity. Ecological Indicators. 2016, 62, 147-153.

102. Ning, J.J.; Du, F.Y.; Wang, X.H.; et al. Trophic connectivity between intertidal and offshore food webs in Mirs Bay; China. Oceanologia. 2019, 61, 208-217.

103. Craig, L.; Clive, N.T.; Francis, N.; et al. Ocean-scale connectivity and life cycle reconstruction in a deep-sea fish. Canadian Journal of Fisheries \& Aquatic Sciences. 2014, 71, 1-12.

104. White, J.W.; Carr, M.; Caselle, J.; et al. Connectivity; Dispersal; and Recruitment, Connecting Benthic Communities and the Coastal Ocean. Oceanography. 2019, 32, 50-59.

105. Avigdor, A.; Halpern, B.S.; Reed, D.C.; et al. Upgrading marine ecosystem restoration using ecological-social concepts. Bioence. 2016, 66, 156-163.

106. Liu, Y.H.; Yang, C.J.; Zhang, P.D.; et al. An Ecopath evaluation of system structure and function for the Laoshan Bay artificial reef zone ecosystem. Acta Ecologica Sinica. 2019, 39, 3926-3936. (In Chinese)

107. Wang, T.; Li, Y.; Xie, B.; et al. Ecosystem Development of Haizhou Bay Ecological Restoration Area from 2003 to 2013. Journal of Ocean University of China, 2017, 16, 1126-1132.

108. Cordova-Lepe; Fernando; Del; et al. The process of connectivity loss during habitat fragmentation and their consequences on population dynamics. Ecological Modelling. 2018, 376, 68-75.

109. Olds, A.D.; Connolly, R.M.; Pitt, K.A.; et al. Quantifying the conservation value of seascape connectivity, a global synthesis. Global Ecology \& Biogeography. 2016, $25,3-15$.

110. Skilleter, G.A.; Loneragan, N.R.; Olds, A.; et al. Connectivity between seagrass and mangroves influences nekton assemblages using nearshore habitats. Marine Ecology Progress. 2017, 573, 25-43.

111. Pikitch, E.K.; Rountos, K.J.; Essington, T.E.; et al. The global contribution of forage fish to marine fisheries and ecosystems. Fish and Fishries. 2014, 15, 43-64.

112. Krystian; Obolewski; Katarzyna; et al. From isolation to connectivity, the effect of floodplain lake restoration on sediments as habitats for macroinvertebrate communities. Aquatic Sciences. 2018, 80, 4.

113. Qin, C.X.; Zhu, W.T.; Ma, H.M.; et al. Are habitat changes driving protist community shifts? A case study in Daya Bay; China. Estuarine; Coastal and Shelf ence. 2019, 227, 106356.

114. Mueller, M.; Geist, J. Conceptual guidelines for the implementation of the ecosystem approach in biodiversity monitoring. Ecosphere. 2016, 7, e01305.

115. Geist, J.; Hawkins, S.J. Habitat recovery and restoration in aquatic ecosystems, current progress and future challenges. Aquatic Conservation Marine and Freshwater Ecosystems. 2016, 26, 942-962. 